\title{
TIME-DEPENDENT DEFORMATION BEHAVIOUR OF STRUCTURES IN SNOW, FIRN OR ICE
}

\author{
by
}

\author{
Rudolf Dörr and Hans L. Jessberger
}

(Department of Civil Engineering, Ruhr University, 4630 Bochum, West Germany)

\section{ABSTRACT}

The time-dependent vertical deformation and the variation of the cross-section of the Georg von Neumayer wintering station, built during the Antarctic summer of 1980-81, are investigated with regard to the rheological behaviour of the surrounding snow, firn, and ice. Computations are performed to determine the time-dependent settlement using the compactive (compressive) viscosity $n_{c}$ as the viscoelastic parameter being a function of the density. $n_{c}$ is derived from the depth-density curve down to to $73.6 \mathrm{~m}$ depth, the initial density $\rho_{0}$, and the accumulation rate. The ground plan and the foundation pressures of the station, and the weight of snow-fill and accumulation, are employed in the analysis, using actual values.

These computations are compared with measurements for a period of $320 \mathrm{~d}$. The described measurement systems include the possibility of finding a reference level in the continuously compressed ice shelf. The time-dependent deformation of experimental tubes is also presented on the basis of convergency data taken over a period of $480 \mathrm{~d}$.

\section{INTRODUCTION}

In connection with the construction of the Georg von Neumayer wintering station on the Ekström ice shelf near Atka Bay, Antarctica, several measuring systems for monitoring the deformations of the station were installed inside and outside the tubes described in Jessberger and Dörr (1982). Immediately after construction was completed, the instruments were set at zero and measurements were recorded during the first wintering period for as long as the instruments were unaffected by weather conditions. During the 1981-82 expedition all measurements were repeated.

A major part of the research project was measurement of the additional vertical settlements of the station compared with the normal compaction of iceshelf ice. The settlements are calculated using the compactive viscosity $n_{C}$ which has been found from the depth-density curve. The calculations are performed for several periods with variable values for $n_{c}$ depending on the densification of firn and ice layers under the load of the station. Settlements take place with time proportional to stresses from this load, snow-fill and dead-weight. The calculated values are compared with the measured settlements and the results are discussed.

For two significant profiles, measurements of the deformation of the cross-section of the tubes and their time-dependent change during $480 \mathrm{~d}$ since construction of the station are reported and discussed.

\section{DEPTH-DENSITY RELATIONSHIP}

The depth-density distribution at Georg von Neumayer station is known from several cores bored down to $10 \mathrm{~m}$ depth and one hole drilled down to $73.6 \mathrm{~m}$ (Fig.1) with recently-developed equipment. Comparisons with other reported depth-density curves show a good agreement with the data of Tongiorgi and others (1962) from Roi Baudouin base. Schytt (1958) found slightly smaller values at Maudheim station. The discontinuities in the density of the upper $10 \mathrm{~m}$ depend on the stratigraphy and are the result of climatic conditions with temperatures above $0^{\circ} \mathrm{C}$ in summer The initial density $p_{0}$, deduced from Figure 1 , is $0.4 \mathrm{~g} \mathrm{~cm}^{-3}$, and the rate of snow accumulation found by Reinwarth and others (1982) is $75 \mathrm{~cm} \mathrm{a}^{-1}$.

3. COMPACTIVE VISCOSITY $n_{C}$

In order to calculate the compactive viscosity a depth-density curve, which approximates the actual

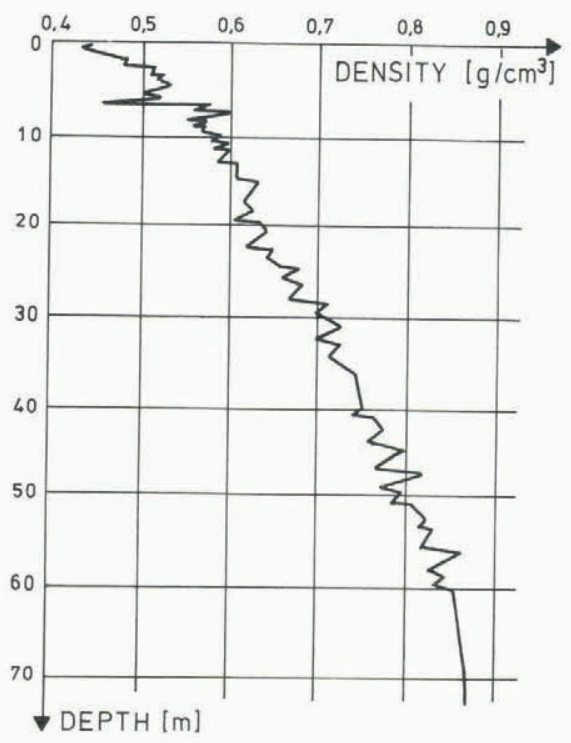

Fig.1. Depth-density curve for Georg von Neumayer station. 

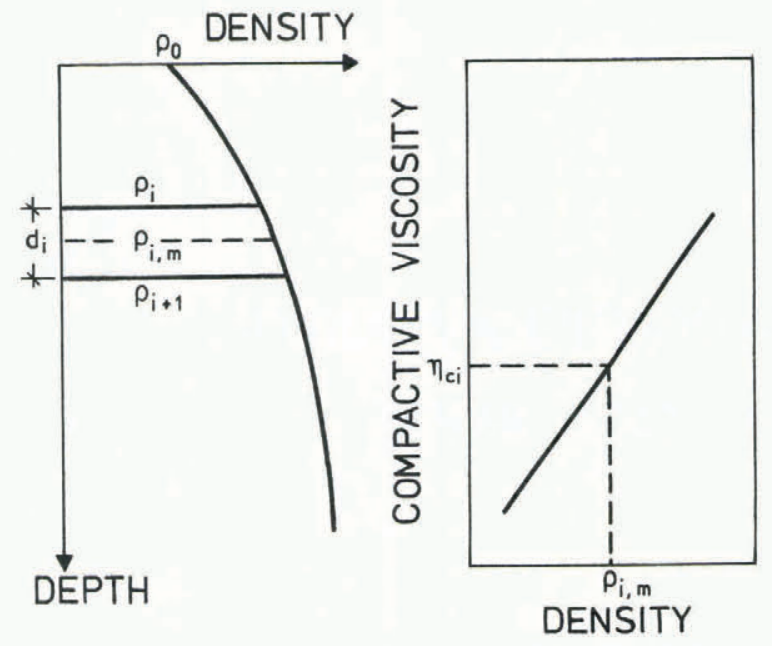

Fig.2. Calculation of compactive viscosity $n_{c}$.

stratigraphy, was used, following a proposal of Bergen (1978). In Figure 2 the compression $\varepsilon_{i}$ of a chosen layer of thickness $d_{i}$ is deduced by the increase of density from $\rho_{i}$ to $\rho_{j+1}$ during time $T_{j}$, giving the equations

$$
\varepsilon_{i}=1-\rho_{j} / \rho_{j+1}
$$

and

$$
T_{i}=\frac{1}{2}\left(\rho_{i}+\rho_{i+1}\right) \frac{1}{\rho_{o} A} \quad d_{i},
$$

where $A$ is the accumulation rate in $\mathrm{cm}$ of snow and $\rho_{0}$ is initial density in $\mathrm{g} \mathrm{cm}^{-3}$.

The load causing the compression of the actual layer is summed up from the overlying layers to

$$
\sigma=\sum_{n=1}^{i} \rho_{i}, m \cdot d_{i},
$$

where

$$
\rho_{i, m}=\frac{1}{2}\left(\rho_{i}+\rho_{i+1}\right) .
$$

The density-dependent compactive viscosity $n_{c}$ can now be computed directly from the depth-density curve:

$$
n_{C i}=T_{i} \cdot \frac{\sum \rho_{i, m} \cdot d_{i}}{\varepsilon_{i}} .
$$

Using Equation (4) the half-space is divided into several layers and $n_{c j}$ is plotted versus $\rho_{i}, m$ for each layer in a semi-logarithmic scale (Fig. 3 ). Magnitude and shape of the curve through these points agree well with results of other authors (Ramseier and Pavlak 1964, Bader and Kuroiwa 1962) and the equation

$$
n_{C}=n_{0} \exp \left(b\left(\rho-\rho_{0}\right)\right)
$$

is used to represent the curve for Georg von Neumayer station, when values of

$$
\begin{aligned}
& n_{0}=6 \times 10^{12} \mathrm{Pas} \\
& b=31.66 \\
& \rho_{0}=0.4 \mathrm{~g} \mathrm{~cm}^{-3}
\end{aligned}
$$

have been found to represent accurately viscosity in the range of $0.4<p<0.65$. The plot of Figure 3 is al so shown in Figure 4 , together with the values obtained by Mellor (1975), and it can be seen that it runs slightly lower than the other values in a similar range of density. The reason may be the higher mean annual temperature of $-17^{\circ} \mathrm{C}$ at Georg von Neumayer station (Reinwarth and others 1982).

\section{COMPUTATIONS OF SETTLEMENTS}

Settlement rates under loads on snow, firn or ice are determined by the viscoelastic properties

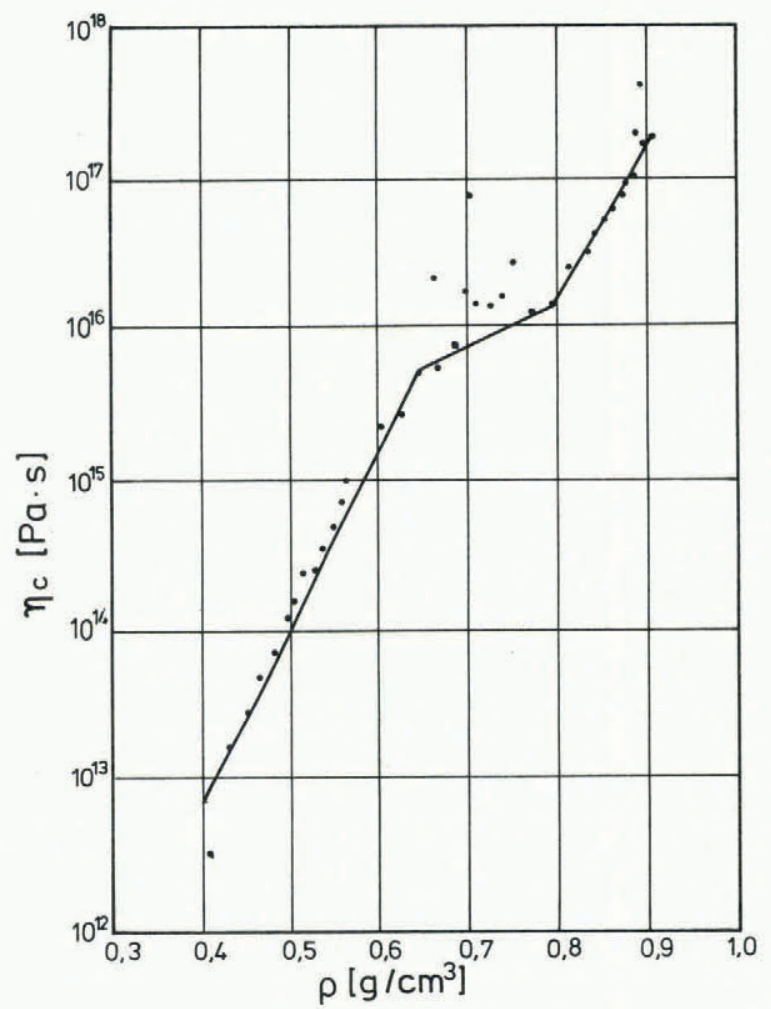

Fig.3. $n_{C}$ versus density for Georg von Neumayer station.

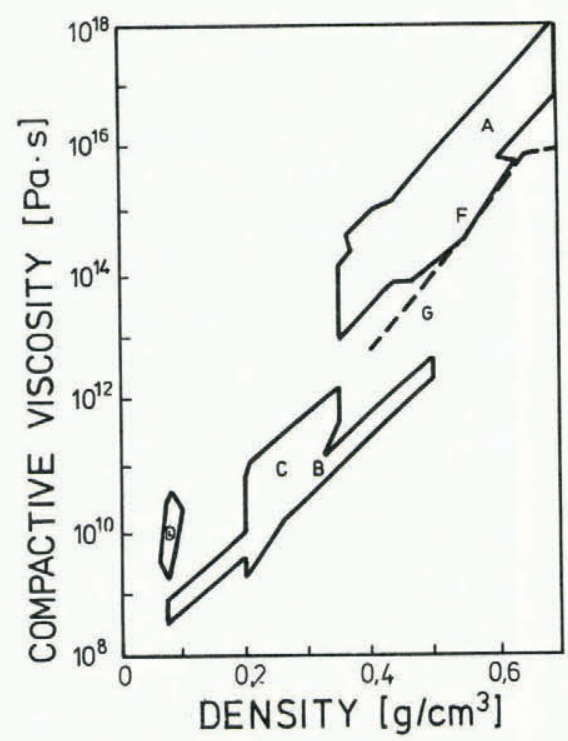

Fig.4. Comparison of compactive viscosities of Mellor (1975) with values from Georg von Neumayer station (dashed line). 
of the materials. After removing the upper $1.5 \mathrm{~m}$, only firn and ice are influenced by the foundation, and the deformations can be represented by a Maxwel model under constant applied stress:

$$
\varepsilon=\sigma / E_{1}+\sigma t / n_{c}(\rho)
$$

where $\sigma$ is applied stress, $E_{1}$ is Young's modulus of elasticity, $t$ is time, and $n_{c}$ is compactive viscosity. Normally the elastic deformation $\sigma / E_{1}$ can be neglected because of the magnitude of $E_{1}$. The loads caused at a foundation depth of $1.5 \mathrm{~m}$ under the snow surface of 1980-81 by station loads and by snow-fill are shown in Figure 5. In the
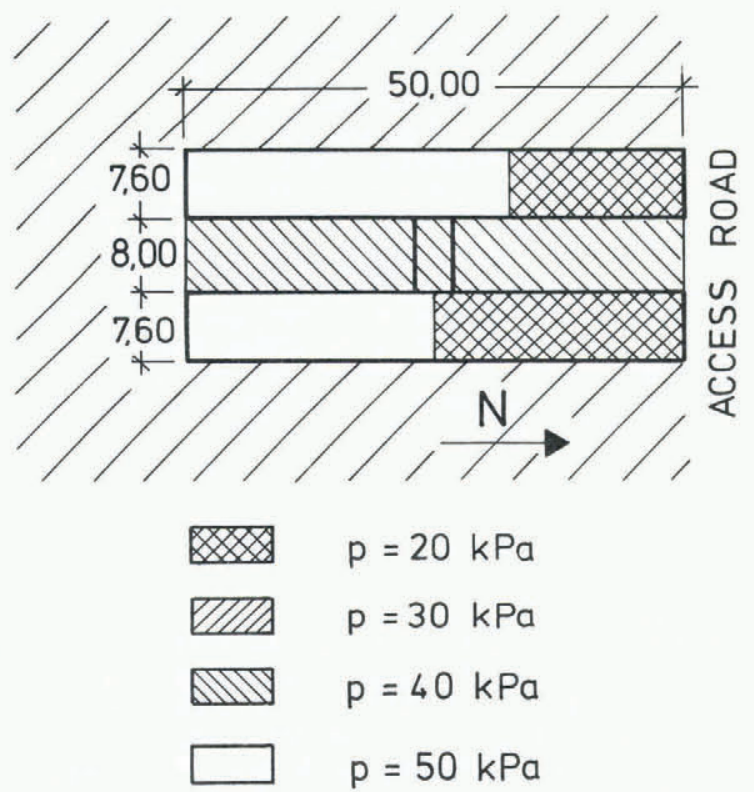

Fig.5. Load distribution for the calculation of settlements.

northern part of the station, snow-fill has not occurred because of the presence of the access road to the tubes. Different foundation pressures of the station depend on the installations inside the tubes. Outside the station a mean density of the snow-fill of $0.55 \mathrm{~g} \mathrm{~cm}^{-3}$ has been found.

From these loads, vertical stresses in the underlying medium are calculated with the Boussinesque solution for the half-space intersected into a certain number of layers. For each layer the stresses caused from the station and the snow-fill were calculated, and the dead-weight of firn and ice was added:

$$
\sigma=\frac{\sigma_{0}+\sigma_{u}}{2}+\sum_{i=1}^{1} \rho_{i, m} \cdot d_{i},
$$

where 1 is the number of overlying layers and $d_{i}$ is the thickness of each layer. Because of the relation between $\rho$ and $n_{0}$ the compression of the single layers means an increase of density and an increase of compactive viscosity $n_{C}$. Therefore the computation of settlements has been divided into several periods. After each period the density and the compactive viscosity were calculated again according to Equation (5). The viscous part of Equation (6) connected with Equation (7) gives Equation (8) for the settlement of one point of the loaded surface:

$$
s=\sum_{j=1}^{k} \sum_{i=1}^{n} \frac{\sigma_{j} \cdot t_{j}}{n_{i, j}} \cdot d_{i, j},
$$

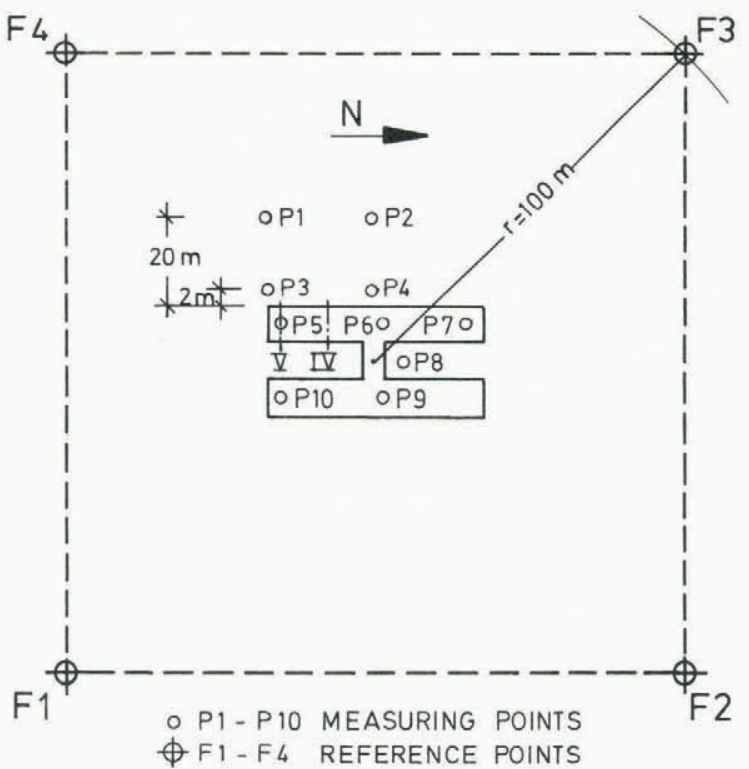

Fig.6. Position of measuring and reference points. where $k$ is the number of periods with $\sum_{j=1}^{k} t_{j}=320 d$ and $n$ is the number of layers. The results of this calculation for points P5 to P10 (A'), P6 to P9 (M), and P10 (A) inside the station (Fig.6) are shown in Figure 7 .

\section{MEASUREMENT OF SETTLEMENTS}

For measurements of the vertical deformations underneath and outside the tubes, extensiometers (Jessberger and Dörr 1982) were installed in bore holes down to $10 \mathrm{~m}$ depth (P1 to P10 in Fig.6). Reference points ( $F 1$ to F4) were placed at a distance of about $100 \mathrm{~m}$ from the station. It is assumed that each of these reference points behaves similarly and shows the general compression of the ice-shelf ice by dead-weight and the annual accumulation. Compared with the reference points, the measuring points inside the station settle more quickly because the loads from the station are an order of magnitude greater than the annual accumulation at the reference points. These settlements after $320 \mathrm{~d}$ are shown in Figure 7.

The measurements of the settlements show good agreement with the results of the computations. Com-
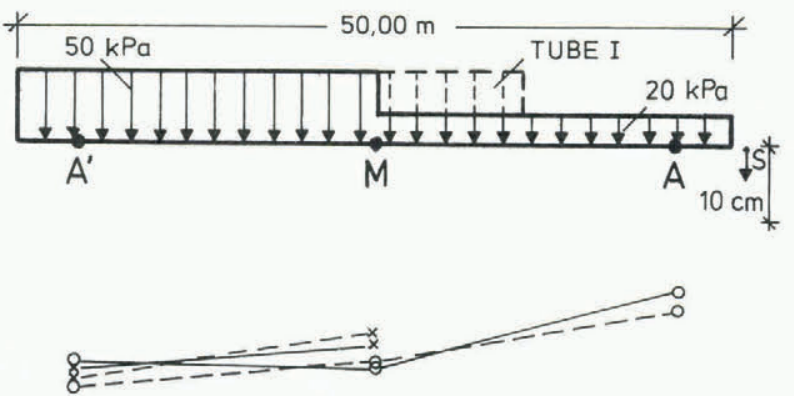

CALCULATED

MEASURED

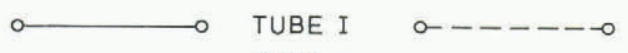

TUBE II $\quad x------x$

Fig.7. Calculated and measured settlements. 
pared with the absolute settlements, the differential settlements between the points of the station are important, because they influence the installations inside. In order to avoid damage to the containers the substructure can be adjusted by a spindletype elevation mechanism.

\section{DEFORMATION OF THE CROSS-SECTION}

The construction of the two station tubes made by steel profiles has the form presented in Figure 8. The containers necessary for the inner instal1ation are led on a flexible substructure. The deformations of the cross-section by the snow-fill and

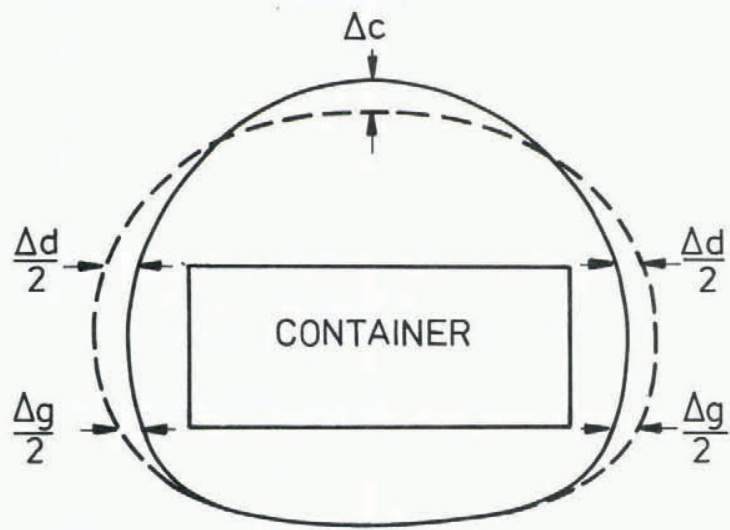

Fig.8. Cross-section of the station and deformations (qualitative).

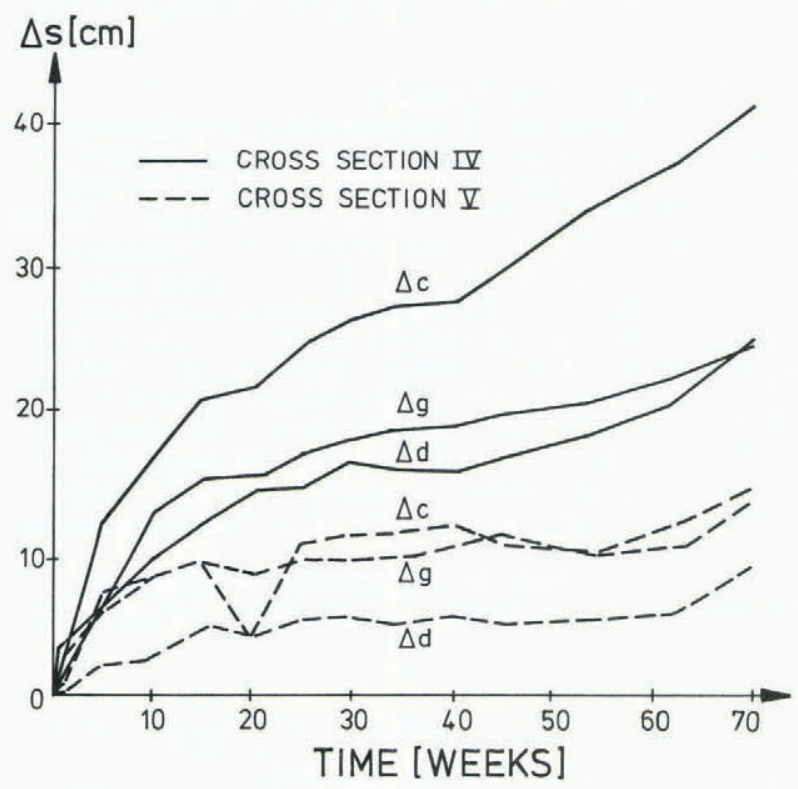

Fig.9. Measured change of distances of the crosssection over $480 \mathrm{~d}$. the accumulation were controlled by measuring several distances between distinct points of eight crosssections distributed over the two tubes. These measurements were also performed during the wintering period. Figure 9 shows two typical examples of the measurements of three distances (Fig.8). It can easily be seen that the deformations of section $V$, positioned near one of the gates (Fig.6), are much less than the deformations of section IV, which indicates that the gates strengthen the construction, thus avoiding greater deformation. Nevertheless the considerable deformations in other sections have to be controlled because they influence installations on the containers.

These deforinations cannot be caused solely by the over-burden snow of about $1 \mathrm{~m}$ after eighteen months. An additional reason can be deduced from the timedependent strain of the ice-shelf ice. Köhler (1982) reported that $\varepsilon_{1}=-1.8 \%$ per year in a northsouth direction (1ongitudinal axis of the station), and $\varepsilon_{2}=+4.0 \%$ per year in an east-west direction (transverse axis of the station). With a length of $50 \mathrm{~m}$ and a total width of $24 \mathrm{~m}$, the deformation of the station area per year is calculated to be $\Delta x_{1}=-9.2 \mathrm{~cm} \mathrm{a}^{-1}$ (compression) and $\Delta \mathrm{x}_{2}=+9.6 \mathrm{~cm} \mathrm{a}^{-1}$ (tension). The deformation $\Delta x_{2}$, acting transverse to the station, causes the movement of the snow surrounding the station away from the structure, reducing the bedding.

\section{CONCLUSIONS}

This paper deals with measurements of deformations of the settlements and change of cross-section at the Georg von Neumayer wintering station over the period of nearly one year. For the vertical settlements, computations for foundations with loads less than $50 \mathrm{kPa}$ are performed using the compactive viscosity as the material parameter for the rheological behaviour. These computations agree with the measurements.

The same measuring system has also been installed during the 1981-82 expedition at the Filchner station (Fig.10). The construction of the station differs from that of Georg von Neumayer station as the containers are located on pile foundations, reaching $2 \mathrm{~m}$ below the snow surface. According to the snow accumulation and the additional settlement rate of the foundations, this station will be jacked up every year to avoid burial with snow.

\section{ACKNOWLEDGEMENTS}

The financial support of the Deutsche Forschungsgemeinschaft and the Bundesministerium für Forschung und Technologie, as well as the work of the wintering parties in 1981 and 1982 and the cooperation of Heinrich Reese during the 1981-82 expedition, are gratefully acknowledged.

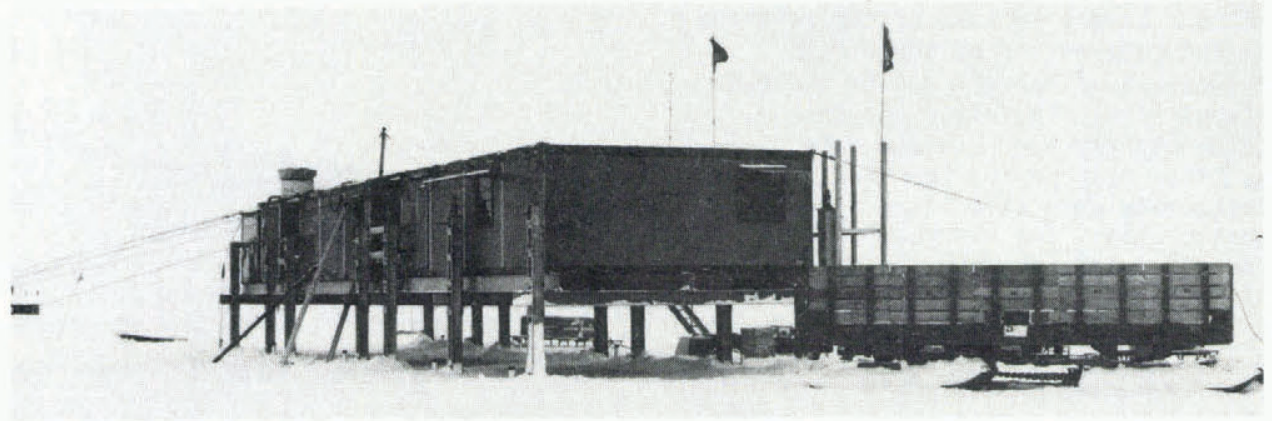

Fig.10. View of Filchner station. 
REFERENCES

Bader H, Kuroiwa D 1962 The physics and mechanics of snow as a material. CRREL Monograph II-B

Bergen J D 1978 Some measurements of settlement in a Rocky Mountains snow cover. Joumal of Glaciology 20(82): 141-148

Jessberger 4 L, Dörr R 1982 Large-scale investigations of the deformation hehaviour of layers of ice shelves. Annals of Glaciology 3: 156-159

Köhler M 1982 Das Verformungsverhalten des EkströmSchelfeises in der Nähe der deutschen AntarktisForschungsstation "Georg-von-Neumayer". Polarforschung $51(2): 60-80$

Mellor M 1975 A review of basic snow mechanics. Intemational Association of Hydrological Sciences Publication 114 (Symposium of Grindelwald 1974 Snow Mechanics): 251-291

Ramseier R 0, Pavlak T L 1964 Unconfined creep of polar snow. Joumal of Glaciology 5(39): 325-332 Reinwarth 0, Rauert ' $\mathrm{N}$, Stichler W, Moser H 1982 Preliminary investigations on accumulation at the Filchner/Ronne ice shelves and Atka Bay. Annals of Glaciology 3: 274-278

Schytt V 1958 Glaciology II. Norwegian-BritishSwedish Antaretic Expedition 1949-1952. Scientific ResuZts IV

Tongiorgi E, Picciotto E, De Breuck W, Norling T, Giot J, Pantanetti F 1962 Deep drilling at Base Roi Boudoin, Dronning Maud Land, Antarctica. Journal of Glaciology 4(31): 101-110 